\title{
Pattern Recognition and Classification Using Backpropagation Neural Network Algorithm for Songket Motifs Image Retrieval
}

\author{
Yuhandri $^{\# 1}$, Sarifuddin Madenda ${ }^{* 1}$, Eri Prasetyo Wibowo ${ }^{* 2}$, Karmilasari ${ }^{* 3}$ \\ \# Faculty of Computer Science, Universitas Putra Indonesia YPTK, Padang-West Sumatera, 25221, Indonesia \\ E-mail: yuyu@upiyptk.ac.id \\ * Faculty of Computer Science, Gunadarma University, Jakarta, 16424, Indonesia \\ E-mail: ${ }^{1}$ sarif@staff.gunadarma.ac.id; ${ }^{2}$ eri@staff.gunadarma.ac.id; ${ }^{3}$ karmila@staff.gunadarma.ac.id
}

\begin{abstract}
This paper proposes a method of extraction, classification and pattern recognition songket cloth texture. Features Chaincode pattern texture (Chain-code pattern texture features) are used as the basis songket search in the database or referred to as a texture-based songket pattern recognition which is part of a content-based image retrieval (CBIR). This method consists of two parts: the first is the process of establishing databases feature Chain-code pattern texture songket and training process of pattern recognition using backpropagation neural network (BPNN), the second is the retrieval process to recognize the pattern songket (songket pattern recognition and retrieval). The proposed method is a combination of several algorithms: color image segmentation, binarization, cropping, edge detection/pattern, feature extraction pattern (probability widened chain-code datasets) and BPNN training and test. Results of tests on $\mathbf{4 0}$ different songket motifs with training data showing the level of accuracy of the proposed method. Results of tests on 40 songket motifs show a good degree of accuracy of proposed method where the precision value reached $98 \%$ and recall value reached $99 \%$.
\end{abstract}

Keywords - songket; moore; chain code; CBIR; BPNN; neuron; precision value; recall value

\section{INTRODUCTION}

Digital image processing field has been widely applied in various areas including the one of which is the application of content-based image retrieval (CBIR). The term CBIR was first appointed by Kato in 1992 [1].Imagery content in the form of color, shape, and texture of the object in the image is the main content of which is used to identify the image retrieval process [2]. Identify retrieval process refers to the similarity distance feature color, shape, and texture between the two images. Besides the three content images, each image can also include additional text that is done manually with the aim to facilitate the categorization of many images.

Some research on CBIR with various approaches have been made since the last decade [3] and continues to date in the field of application. The primary target of CBIR is to seek and find images in large-scale image databases that have similar content or query image according to the user's interests [4].

The main problem is the accuracy in image retrieval methods used in elections, especially in the feature extraction which will determine the value of traits or characteristics of each image. These features are the content of the information contained in each image and then stored in the image database. In this paper, the type of imagery used is the image of songket. Songket is a kind of traditional woven cloth of West Sumatra, where it contains a variety of motives or texture patterns, each of which has a philosophical meaning of life. This suggests that the motif or pattern texture feature is the primary information that can be used for the introduction of this kind of songket. Texture pattern in question is a variation contour shape that forms the object of the motif as seen in Fig. 1 and Fig. 3.

The objective of this research is to propose a method of extraction, classification and pattern recognition songket cloth texture. Features Chain-code pattern texture (Chaincode pattern texture features) are used as the basis songket search in the database, or referred to as a texture-based songket pattern recognition which is part of a content-based image retrieval (CBIR).

\section{MATERIAL AND METHOD}

Fig. 1 shows the image of West Sumatra songket motifs recognized using the Canon EOS 7D digital camera Canon 
EOS 7D. Songket has a homogeneous color background and has the distinction of color motif. One type of songket can be made with different background colors but still have the same motif. To create a computer to recognize the themes of what is contained in the image of songket, we propose a method of extraction, classification and pattern recognition songket cloth texture. The order of the process of the proposed method is shown in Fig. 2. This method is divided into two phases: the first phase of the establishment of a database of chain-code feature texture patterns and training, and the second phase is the testing or songket pattern recognition and retrieval.

\section{A. Pre-processing}

Pre-processing is to separate the color motif of the background color, so that it will facilitate the detection process banks of objects motifs and patterns of her search to determine the probability Chain-code from any such motives. Pre-processing consists of color segmentation algorithm, binarization, cropping and edge detection.
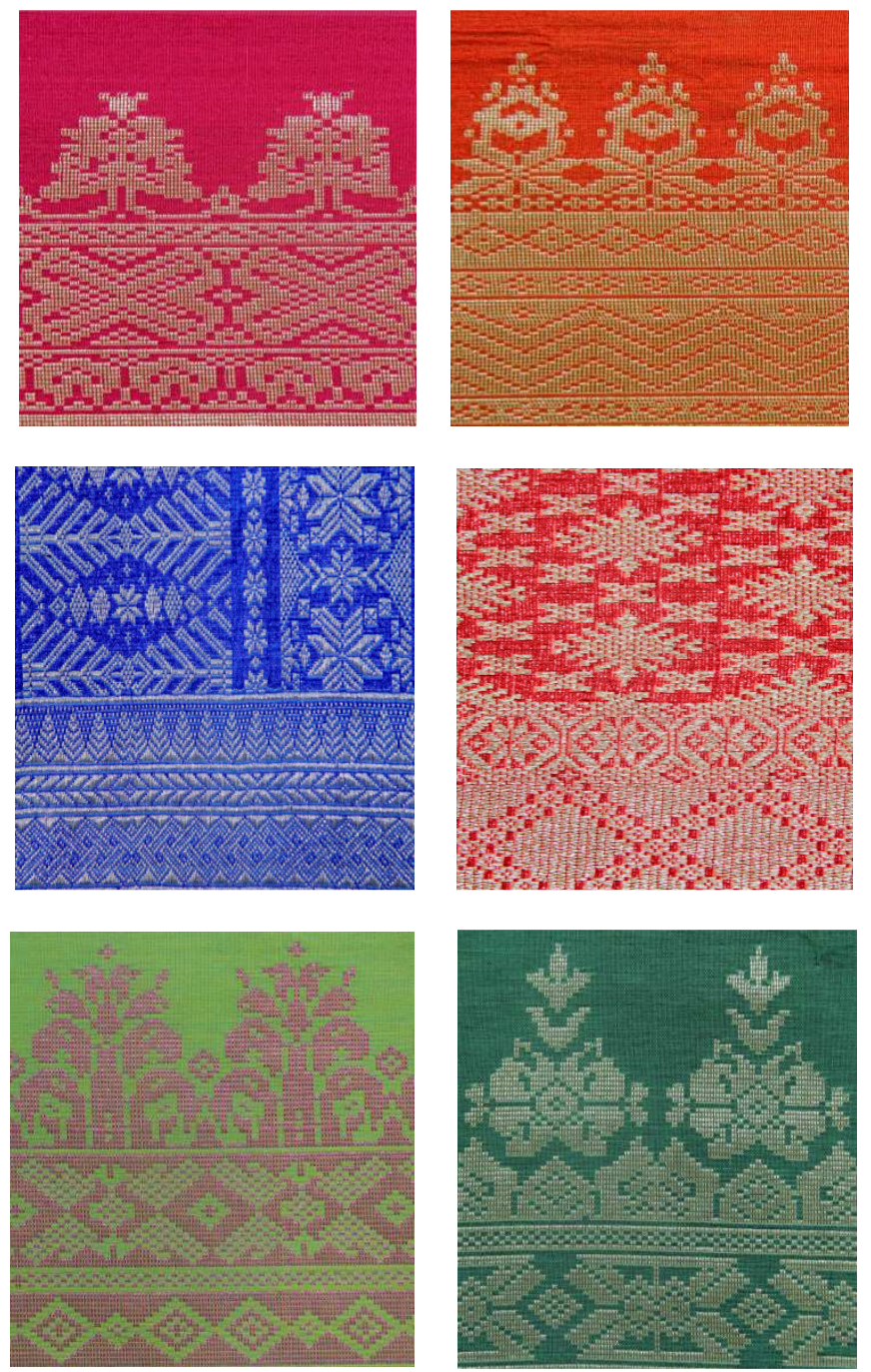

Fig. 1 Original image songket

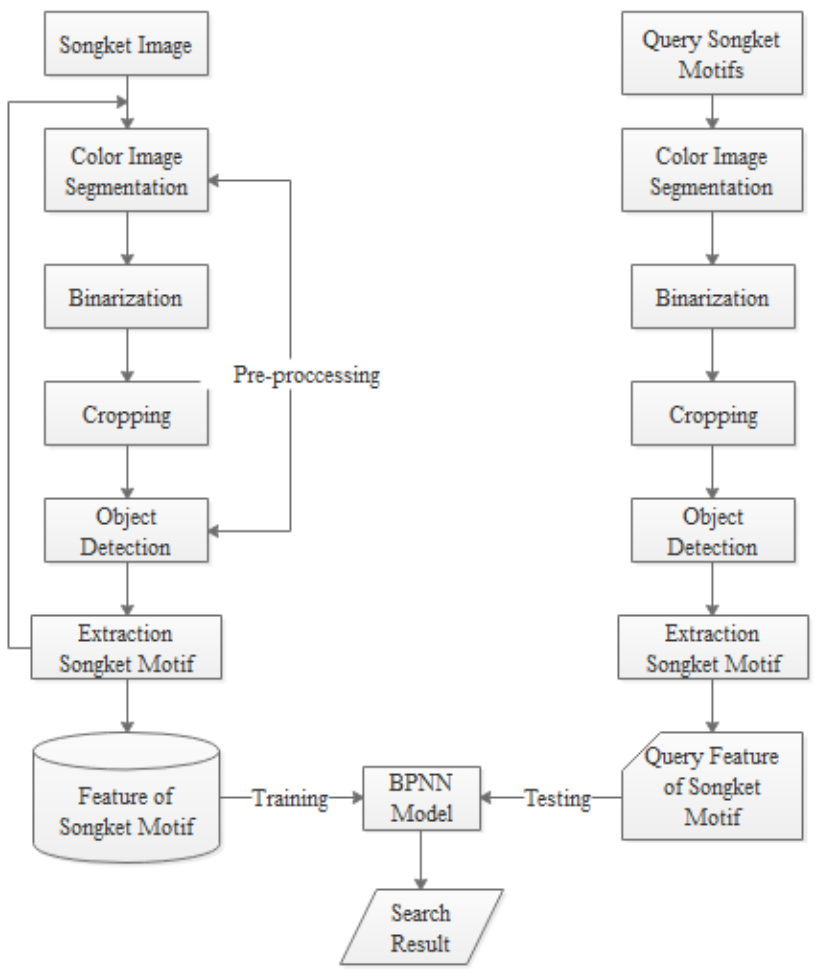

Fig. 2 Stages classification and retrieval system-recognized songket motifs

\section{1) Color Image Segmentation}

The segmentation process is based on the similarity in color between the color of each pixel against the background color songket. RGB color space and Euclidean distance is used to measure the distance between the two colors. RGB color Euclidean distance formula given by equation (1):

$$
D=\sqrt{\left(R_{r e f}-R_{p}\right)^{2}+\left(G_{r e f}-G_{p}\right)^{2}+\left(B_{r e f}-B_{p}\right)^{2}}
$$

Where $R_{\text {ref }}, G_{\text {ref }}$ and $B_{\text {ref }}$, each of which is a component of red, green and blue color background reference of songket. $R_{p}, G_{p}$ and $B_{p}$, respectively the three color components of each pixel in the image.

The basic principles of color segmentation of songket motifs is to remove all pixels that have the same color or background color approaching songket $(\mathrm{D}<\mathrm{Th}$ ) and take all the pixels that have a color distance $\mathrm{D}>\mathrm{Th}$. Th threshold value which can be determined is based on the results of the experiment [5]. Fig. 3 shows the results of a sample of color segmentation process, in which all the motifs can be segmented properly and had separated from the background color.

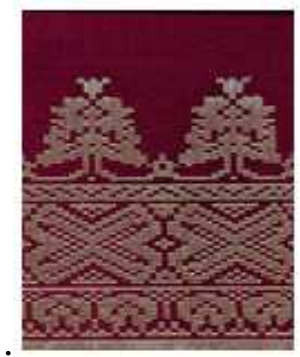

Fig. 3 Examples of segmentation results songket motifs 


\section{2) Binarization}

A binarization process is carried out to facilitate the pattern recognition analysis of the results of image segmentation motif (Fig. 3). This process just change all colors become white motif with a binary value of "1" and a black background with a binary value "0" [6] [7]. Binarization function is given by equation (2) where binarization itself is to simplify the process of pattern recognition, since the pattern will be more easily detected in the images that contain fewer colors, can be seen in equation 2.

$$
g(x, y)=\left\{\begin{array}{l}
0, \text { if } f(x, y)<T \\
1, \text { if } f(x, y) \geq T
\end{array}\right.
$$

Where $\mathrm{g}(\mathrm{x}, \mathrm{y})$ is a binary image of the image segmentation result $f(x, y)$ and $T$ stated threshold value. Example binarization songket motifs segmentation results are shown in Fig. 4.

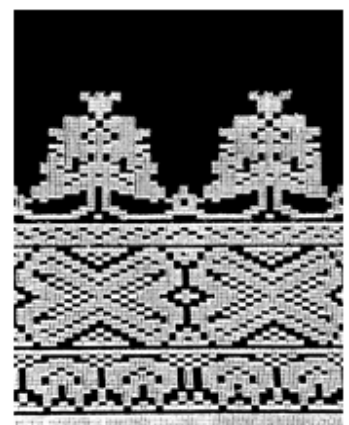

Fig. 4 Sample results songket motifs binarization

\section{3) The process of cropping}

There are several pattern of songket motifs, as seen in the image of the binarization. Each pattern that exist in an image needs to be separated from one to another. Motif pattern separation is done through a process of cropping. Cropping refers to the boundary between the pattern with other patterns or the size of the motif pattern. Fig. 5 shows 20 patterns of songket motifs cropping results. Furthermore, this motif is used for feature extraction pattern as the main characteristics of each of these motifs.

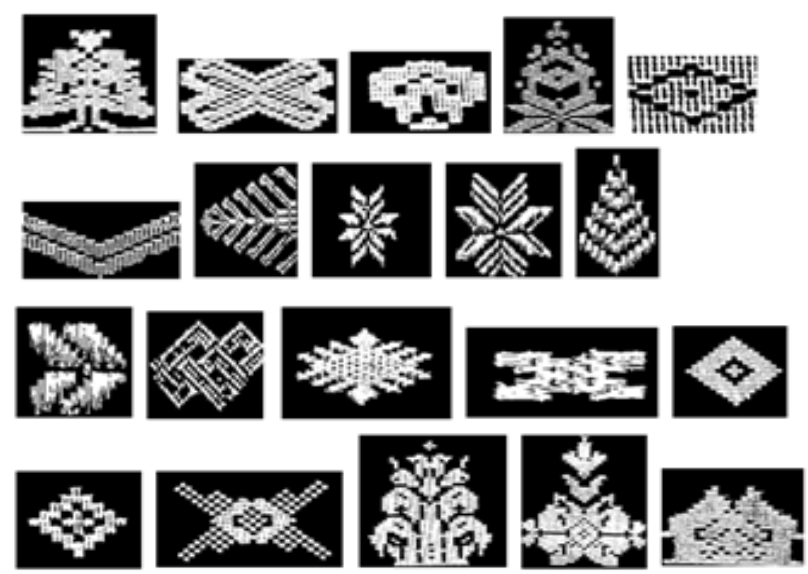

Fig. 5. Motif cropping results

\section{4) Object Detection}

Fig. 5 show that every motif is characterized by the different patterns. Such traits can be divided into two parts, namely global traits or forms of global and specific features or detailed form. Shape the details in question include the dots (holes) in the form of global black. Both can be used to distinguish one motif with other motifs. But, from the global shape alone is enough to distinguish these motives. For that, we only use global pattern characteristics as the differentiating features between songket motifs. To facilitate the global hallmark extracting pattern motif, first needs to eliminate / closing holes that are characteristic filing details through holes [8] [9]. Once that is done the edge detection process using mathematical morphology which is the difference between the results of morphological dilation and binary image.

$$
\begin{aligned}
M & =F \oplus B \\
\text { Cont } & =|F-M|
\end{aligned}
$$

where $\mathrm{F}$ is a binary image, $\mathrm{B}$ is a structural element, $\mathrm{M}$ is the image of the morphological dilation is expressed by the symbol $\bigoplus$ and $\mathrm{C}_{\text {ont }}$ stated countur image. Fig. 6 shows an example countur of global forms a motif after going through the process of thinning.

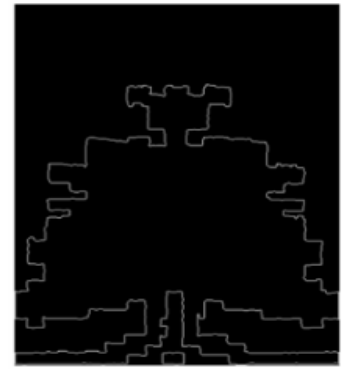

Fig. 6 Example contours of global forms a motif

\section{B) Motif Feature Extraction}

Contours which have been obtained describe the shape or pattern of songket motifs. This means that features a pattern can be used to distinguish one motif with other motifs. This pattern features can be extracted via search or inbound contour tracing algorithms using moore and Chain-code [10] [11]. It is known that the weakness of the Chain-code is a code obtained will always be different if there is a change of geometric rotation and zooming on a motive. To anticipate changes in the geometric zooming, we use a probability value Chain-code as a feature of each motif pattern of songket. Moderate to minimize errors due to geometric changes in the rotation, then in the process of training to use some sample for each motif.

Table 1 shows the results of calculation of probability Chain-code of 20 types of motifs, each motif is represented by a sample of up to 4 samples. Column 1-8 sequentially a probability value Chain-code $0-7$, while in column 9 expressed a sample of the type of motif to-i. Value-Chaincode the probability value is expressed as a feature pattern and stored in a database and used for the training process. 
TABLE I

SET DATA ExTRACTION OF MOTIFS OF SONGKET

\begin{tabular}{|c|c|c|c|c|c|c|c|c|}
\hline & 1 & 2 & 3 & 4 & 5 & 6 & 7 & 9 \\
\hline 1 & 0,2656 & 0,0309 & 0,1689 & 0,0306 & 0,2737 & 0,0303 & $0,16190,0381$ & 1 \\
\hline 2 & 0,2530 & 0,0241 & 0,1687 & 0,0241 & 0,3012 & 0,0120 & $0,18070,0361$ & 1 \\
\hline 3 & 0,2614 & 0,0316 & 0,1725 & 0,0312 & 0,2670 & 0,0308 & $0,16990,0355$ & 52 \\
\hline 4 & 0,2022 & 0,0467 & 0,2011 & 0,0446 & 0,2109 & 0,0370 & $0,21520,0424$ & 43 \\
\hline 5 & 0,1832 & 0,0300 & 0,2252 & 0,0721 & 0,1622 & 0,0390 & $0,2282 \quad 0,0601$ & 4 \\
\hline 6 & 0,2619 & 0,0357 & 0,1667 & 0,0238 & 0,2857 & 0,0238 & $0,16670,0357$ & \\
\hline 7 & 0,1915 & 0,0340 & 0,2383 & 0,0426 & 0,1787 & 0,0298 & $0,25960,0255$ & 54 \\
\hline 8 & 0,2499 & 0,0424 & 0,1651 & 0,0435 & 0,2482 & 0,0414 & $0,16890,0407$ & 74 \\
\hline 9 & 0,2308 & 0,0192 & 0,2212 & 0,0385 & 0,2115 & 0,0288 & $0,22120,0288$ & 34 \\
\hline 0 & 0,1942 & 0,0291 & 0,2233 & 0,0291 & 0,2233 & 0,0291 & $0,21360,0583$ & 34 \\
\hline 11 & 0,0793 & 0,0144 & 0,2608 & 0,0144 & 0,3401 & 0,0187 & $0,2522 \quad 0,0202$ & 25 \\
\hline 2 & 0,0556 & 0,0151 & 0,1525 & 0,0143 & 0,5798 & 0,0191 & $0,15010,0135$ & 56 \\
\hline 3 & 0,1765 & 0,0374 & 0,2193 & 0,0615 & 0,1872 & 0,0267 & $0,22990,0615$ & 57 \\
\hline 4 & 0,1696 & 0,0408 & 0,2534 & 0,0448 & 0,1525 & 0,0530 & $0,24600,0399$ & 7 \\
\hline 5 & 0,1713 & 0,0498 & 0,2461 & 0,0343 & 0,1651 & 0,0530 & $0,2555 \quad 0,0249$ & 7 \\
\hline 6 & 0,1564 & 0,0491 & 0,2555 & 0,0408 & 0,1521 & 0,0451 & $0,26910,0320$ & 8 \\
\hline 17 & 0,0921 & 0,0316 & 0,2605 & 0,0395 & 0,2421 & 0,0342 & $0,26320,0368$ & 39 \\
\hline 8 & 0,1496 & 0,0474 & 0,2392 & 0,0632 & 0,1496 & 0,0443 & $0,2487 \quad 0,0580$ & 10 \\
\hline 9 & 0,2986 & 0,0313 & 0,1363 & 0,0417 & 0,2821 & 0,0365 & $0,14500,0286$ & 511 \\
\hline 20 & 0,1652 & 0,0341 & 0,2657 & 0,0395 & 0,1544 & 0,0521 & $0,24600,0431$ & 12 \\
\hline 21 & 0,2838 & 0,0135 & 0,1757 & 0,0405 & 0,2568 & 0,0270 & $0,1757 \quad 0,0270$ & 13 \\
\hline 22 & 0,2848 & 0,0347 & 0,1369 & 0,0442 & 0,2837 & 0,0325 & $0,14240,0409$ & 13 \\
\hline 23 & 0,3062 & 0,0349 & 0,1318 & 0,0349 & 0,2907 & 0,0388 & $0,13950,0233$ & 313 \\
\hline 24 & 0,1967 & 0,0164 & 0,2295 & 0,0164 & 0,2787 & 0,0164 & $0,14750,0984$ & +13 \\
\hline 25 & 0,2931 & 0,0345 & 0,1379 & 0,0345 & 0,2586 & 0,0690 & $0,13790,0345$ & 513 \\
\hline 26 & 0,3354 & 0,0280 & 0,1071 & 0,0326 & 0,3261 & 0,0311 & $0,11340,0264$ & +14 \\
\hline 27 & 0,2477 & 0,0180 & 0,2162 & 0,0450 & 0,1937 & 0,0586 & $0,18920,0315$ & 515 \\
\hline 28 & 0,2534 & 0,0339 & 0,1762 & 0,0415 & 0,2434 & 0,0406 & $0,17280,0382$ & 215 \\
\hline 29 & 0,4000 & 0,0000 & 0,0000 & 0,0000 & 0,4000 & 0,0000 & $0,20000,0000$ & 15 \\
\hline 30 & 0,1905 & 0,0420 & 0,2002 & 0,0624 & 0,1991 & 0,0560 & $0,18620,0635$ & 516 \\
\hline 31 & 0,0000 & 0,0034 & 0,3039 & 0,0509 & 0,2835 & 0,0492 & $0,30560,0034$ & +17 \\
\hline 32 & 0,2107 & 0,0377 & 0,2028 & 0,0377 & 0,2327 & 0,0346 & $0,18710,0566$ & 517 \\
\hline 33 & 0,1991 & 0,0389 & 0,2169 & 0,0245 & 0,2380 & 0,0234 & $0,21250,0467$ & 77 \\
\hline 34 & 0,1006 & 0,0112 & 0,2081 & 0,0280 & 0,4050 & 0,0186 & $0,21180,0168$ & 318 \\
\hline 35 & 0,1887 & 0,0063 & 0,3145 & 0,0000 & 0,1698 & 0,0566 & $0,23270,0314$ & +18 \\
\hline 36 & 0,2000 & 0,0000 & 0,2000 & 0,0000 & 0,2000 & 0,0000 & $0,4000 \quad 0,0000$ & 18 \\
\hline 37 & 0,1736 & 0,0436 & 0,2415 & 0,0436 & 0,1688 & 0,0514 & $0,23080,0466$ & 519 \\
\hline 38 & 0,1825 & 0,0504 & 0,2137 & 0,0552 & 0,1789 & 0,0492 & $0,21970,0504$ & 419 \\
\hline 39 & 0,1759 & 0,0524 & 0,2162 & 0,0517 & 0,1830 & 0,0504 & $0,21390,0565$ & 519 \\
\hline 40 & 0,1921 & 0,0282 & 0,2467 & 0,0437 & 0,1702 & 0,0385 & $0,24960,0311$ & 20 \\
\hline
\end{tabular}

\section{Classification and Retrieval Recognize Motif of Songket}

Some classification algorithms available today such as decision tree, Bayesian, support vector machine, neural network. Neural network is widely used in the fields of pattern recognition, signal processing, forecasting, classification, optimization, control theory and to solve the problem of regression [12] [13]. Neural network is preferred because it has a dynamic nature that is always able to adapt through a learning process. This paper use the classification model backpropagation neural network (BPNN).

\section{1) Training}

All the algorithms described above have unless implemented and tested using Matlab software, including the training process using an algorithm backpropagation neural network (BPNN). BPNN has 8 input architecture with three layers as shown in Table 2 and the shape of the network shown in Fig. 4.

BPNN training is conducted by using 20 songket motifs as a data base feature songket pattern with extraction results as in Table 1, with the aim that Neural Network can adapt and recognize all the patterns of each sample motif used in this training. Fig. 5 shows a graph of performance training process where the epochs under $100 \mathrm{MSE}$ error value in the order of $10^{\circ}$. The MSE value continues to decrease until it reaches under the order of $10^{-4}$ at the time of training epochs 800. The results are shown in Table 3 .

TABLE II

PRELIMINARY PARAMETERS VALUE

\begin{tabular}{|l|l|}
\hline \multicolumn{1}{|c|}{ Name of Parameter } & \multicolumn{1}{c|}{ Value } \\
\hline Network architecture & $8-100-100-1$ \\
\hline Neuron input & 8 \\
\hline Neuron hidden layer (2) & 100 \\
\hline Neuron output & 1 \\
\hline Learning rate & 0.1 \\
\hline Goal & 0.0001 \\
\hline Epochs & 800 \\
\hline Mc & 0.95 \\
\hline
\end{tabular}

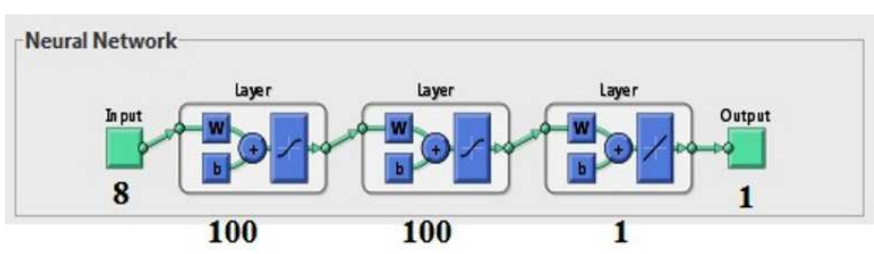

Fig. 4 Architecture BPNN

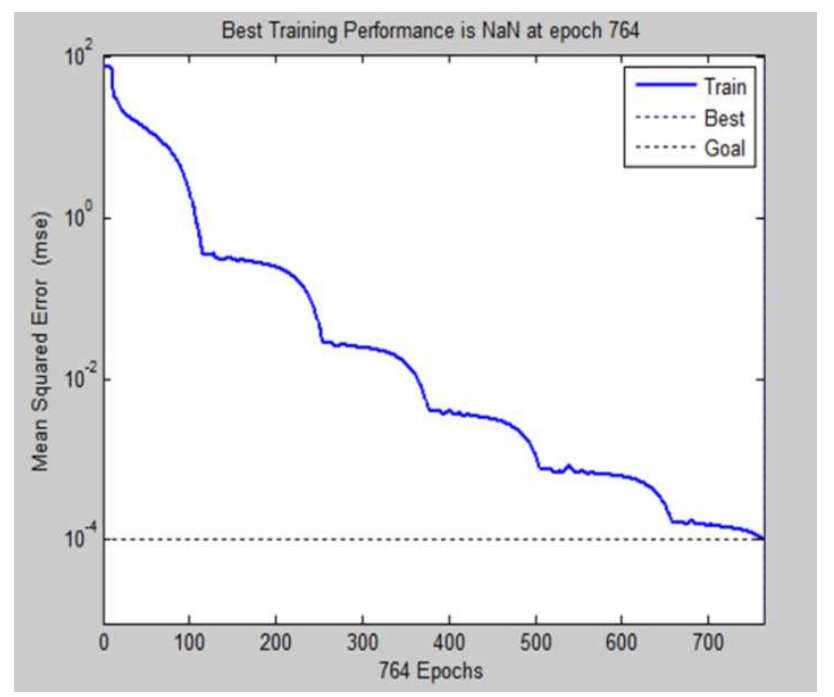

Fig. 5 Graph MSE value changes in training

TABLE III

PARAMETERS OF TRAINING

\begin{tabular}{|l|l|}
\hline \multicolumn{1}{|c|}{ Parameters } & \multicolumn{1}{c|}{ Result } \\
\hline MSE & 0.00009900 \\
\hline Epochs & 764 \\
\hline Gradient & 0.010145 \\
\hline Learning Rate & 0.058066 \\
\hline
\end{tabular}


Evaluation of the training process is done by using a regression analysis of the response and the target tissue. The results of this evaluation are shown by the graph in Fig. 6 . The graph shows the results of linear regression line gradient equal to eleven, the point of intersection on the $\mathrm{Y}$ axis exactly at the point 0 and the correlation coefficient (R) equal to 1 . These results indicate that a lack of compatibility between the output of the same network with the target and thus can predict all training data appropriately.

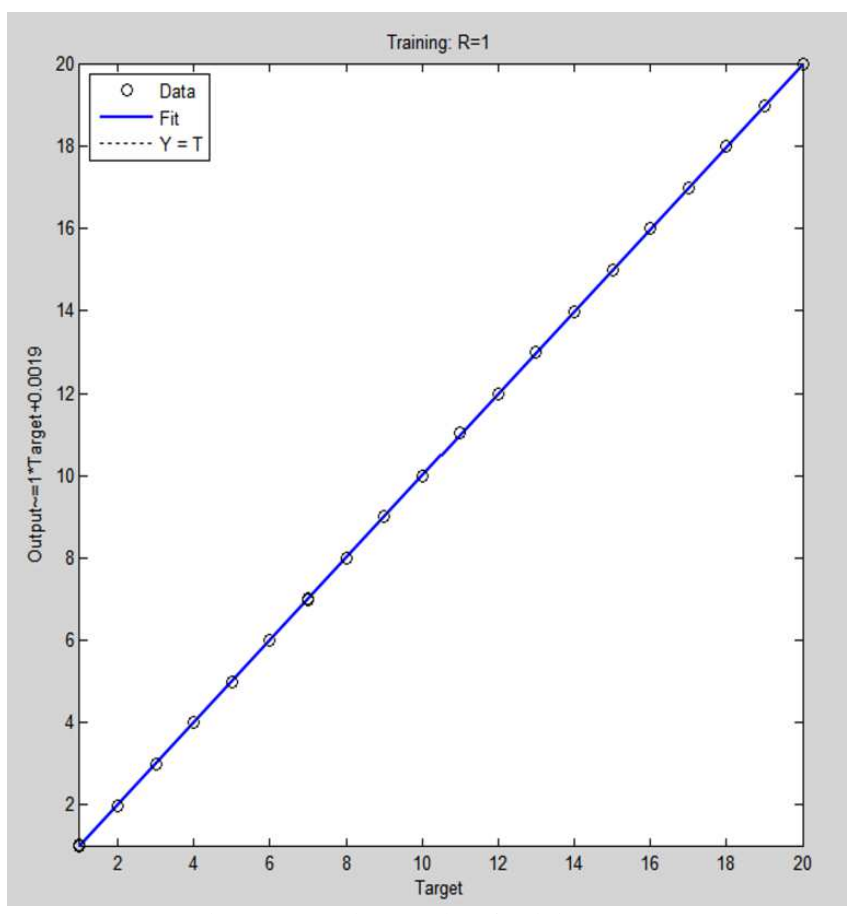

Fig. 6 Regression results of training BPNN

\section{2) Testing}

Testing phase follows the sequence of processes in the chart to the right of Fig. 1. Starting from the segmentation process to the process of feature extraction motif identical to processes performed on the stage of the formation of the database. Results motif pattern features of the query will be recognized by BPNN who have gone through the learning process. Identify the image retrieval system that includes all the above process has been implemented in the GUI as in fig. 7. The GUI has 6 views, namely:

1. Showing information menu consists of input motif, boundary, test, reset.

2. Display the input motif.

3. Results contour songket motifs.

4. Display the probability value Chain-code pattern of songket motifs query.

5. The name of songket motifs recognize the results of the meeting.

6. Explanation of songket production.

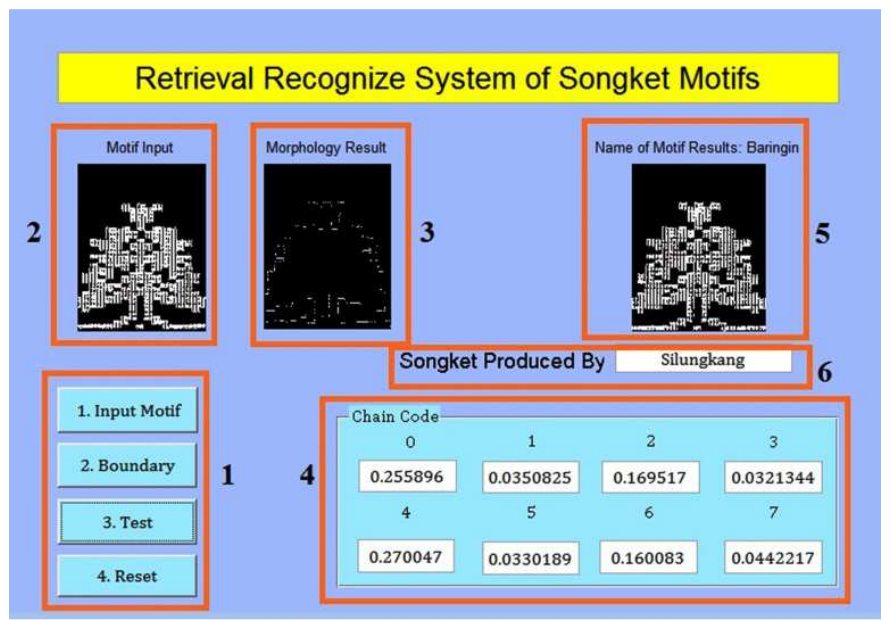

Fig. 7 Stages classification and retrieval system-recognized songket motifs

\section{RESULTS AND DISCUSSION}

In order to get good accuracy of testing time classification data, the training set should be able to represent the state of the test data. To measure the performance of the system used calculation precision and recall. Precision is the degree of accuracy of the information requested by the user with the answers given by the system while the recall is the success rate in finding back the information system. Accuracy in precision and recall can be defined by the formula in Table 4 .

TABLE IV

CONFUSION MATRIX

\begin{tabular}{|c|c|c|c|}
\hline \multicolumn{2}{|c|}{} & \multicolumn{2}{c|}{ Predicted Class } \\
\cline { 3 - 4 } \multicolumn{2}{|c|}{} & Positive & Negative \\
\hline \multirow{2}{*}{$\begin{array}{c}\text { Actual } \\
\text { Class }\end{array}$} & Positive & True Positive (TP) & False Negative (FN) \\
\cline { 2 - 4 } & Negative & False Positive (FP) & True Negative (TN) \\
\hline
\end{tabular}

Based on the table, the formula recall and precision into:[14]

$$
\begin{aligned}
& \text { Precision }=\frac{T P}{T P+F P} \\
& \text { Recall }=\frac{T P}{T P+F N}
\end{aligned}
$$

To evaluate the information retrieval which combines precision and recall can use the calculation of F-measure which is the quality of harmonic mean from the recall and precision, with the following formula:

$$
\text { F-measure }=2 \times \frac{\text { Precision } \times \text { Recall }}{\text { Precision }+ \text { Recall }}
$$

At the time of the test using 80 different motifs with training data, the overall result for the value of precision and recall can be seen in Table 5 and 6 : 
TABLE V

Test Results Of PRecision Value MotiF

\begin{tabular}{|c|l|c|c|c|c|}
\hline No. & Name of Motifs & $\begin{array}{c}\text { Total } \\
\text { Data Test }\end{array}$ & TP & FP & Precision \\
\hline 1 & Baringin & 4 & 4 & 0 & $100 \%$ \\
\hline 2 & Kali & 4 & 4 & 0 & $100 \%$ \\
\hline 3 & Cindawan & 4 & 4 & 0 & $100 \%$ \\
\hline 4 & Mahkota & 4 & 4 & 0 & $100 \%$ \\
\hline 5 & Saik Kalamai & 4 & 4 & 0 & $100 \%$ \\
\hline 6 & Kelok & 4 & 3 & 1 & $75 \%$ \\
\hline 7 & Pucuak Rabuang & 4 & 3 & 1 & $75 \%$ \\
\hline 8 & Pucuak Rabuang & 4 & 4 & 0 & $100 \%$ \\
\hline 9 & Kociak & 4 & 4 & 0 & $100 \%$ \\
\hline 10 & Anyaman & 4 & 4 & 0 & $100 \%$ \\
\hline 11 & Bintang Godang & 4 & 4 & 0 & $100 \%$ \\
\hline 12 & Bintang Kociak & 4 & 4 & 0 & $100 \%$ \\
\hline 13 & Ubur-Ubur & 4 & 4 & 0 & $100 \%$ \\
\hline 14 & Bintang Lauik & 4 & 4 & 0 & $100 \%$ \\
\hline 15 & Tabuik & 4 & 4 & 0 & $100 \%$ \\
\hline 16 & Lopi & 4 & 4 & 0 & $100 \%$ \\
\hline 17 & Marmar & 4 & 4 & 0 & $100 \%$ \\
\hline 18 & Lancip & 4 & 4 & 0 & $100 \%$ \\
\hline 19 & Mahkota Bungo & 4 & 4 & 0 & $100 \%$ \\
\hline 20 & Gonjong & 4 & 4 & 0 & $100 \%$ \\
\hline & & & Average & $98 \%$ \\
\hline
\end{tabular}

TABLE VI

TEst Results of ReCall VALUe MotiF

\begin{tabular}{|c|c|c|c|c|c|}
\hline No. & Name of Motifs & $\begin{array}{c}\text { Total } \\
\text { Data Test }\end{array}$ & $\mathrm{TP}$ & $\mathrm{FN}$ & Recall \\
\hline 1 & Baringin & 4 & 4 & 0 & $100 \%$ \\
\hline 2 & Kali & 4 & 4 & 0 & $100 \%$ \\
\hline 3 & Cindawan & 4 & 4 & 0 & $100 \%$ \\
\hline 4 & Mahkota & 4 & 4 & 0 & $100 \%$ \\
\hline 5 & Saik Kalamai & 4 & 4 & 0 & $100 \%$ \\
\hline 6 & Kelok & 4 & 3 & 1 & $75 \%$ \\
\hline 7 & Pucuak Rabuang & 4 & 4 & 0 & $100 \%$ \\
\hline 8 & $\begin{array}{l}\text { Pucuak Rabuang } \\
\text { Kociak }\end{array}$ & 4 & 4 & 0 & $100 \%$ \\
\hline 9 & Sirip & 4 & 4 & 0 & $100 \%$ \\
\hline 10 & Anyaman & 4 & 4 & 0 & $100 \%$ \\
\hline 11 & Bintang Godang & 4 & 4 & 0 & $100 \%$ \\
\hline 12 & Bintang Kociak & 4 & 4 & 0 & $100 \%$ \\
\hline 13 & Ubur-Ubur & 4 & 4 & 0 & $100 \%$ \\
\hline 14 & Bintang Lauik & 4 & 4 & 0 & $100 \%$ \\
\hline 15 & Tabuik & 4 & 4 & 0 & $100 \%$ \\
\hline 16 & Lopi & 4 & 4 & 0 & $100 \%$ \\
\hline 17 & Marmar & 4 & 4 & 0 & $100 \%$ \\
\hline 18 & Lancip & 4 & 4 & 0 & $100 \%$ \\
\hline 19 & Mahkota Bungo & 4 & 4 & 0 & $100 \%$ \\
\hline 20 & Gonjong & 4 & 4 & 0 & $100 \%$ \\
\hline
\end{tabular}

Table 5 and Table 6 shows that 20 kinds of motifs where each motif is represented by four motifs, so the total motif tested was 80 motifs. The average value of precision results from testing of songket motifs amounted to $98 \%$ and recall value amounted to $99 \%$ on $0 \%-100 \%$ scale. The precision value is lower than the recall value. Retrieval system identifies the motifs of songket can be said effective although precision value is smaller than the recall value by the theory raised by Lancaster [15]. The effectiveness of retrieval recognizes distinguished information becomes effective if the value above $50 \%$ and ineffective if the value is below the value of 50\%. According to Pao [16] if the ratio of recall and precision equal (1:1), the retrieval system can be said to be recognized under ideal conditions. The result of precision and recall were evaluated by using F-measured to show the mutual relations between precision and recall, which is obtained F-measure value of 0.9849 . The Fmeasured result is close to 1 , it means that the precision and recall results show good accuracy.

Graph of precision results can be seen in Fig. 8.

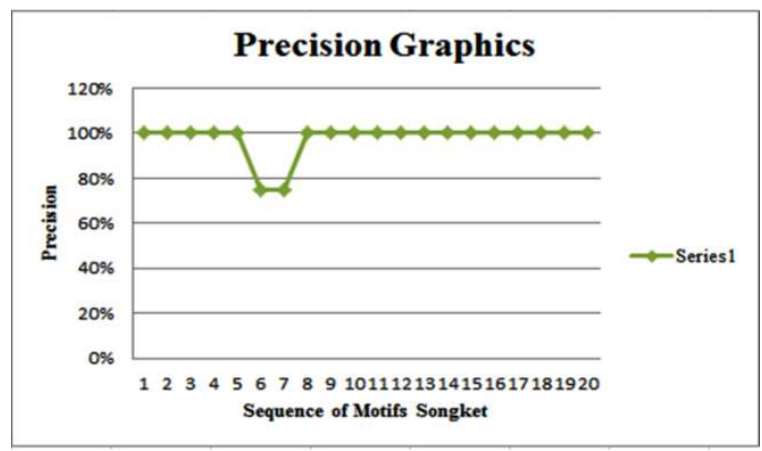

Fig. 8 Graph results precision whole motif songket

Fig. 8 shows the $6^{\text {th }}, 7^{\text {th }}$ motifs ("twist" motifs, "grandchildren"), where each of the four motive test scores obtained each precision by $75 \%$ at the time of testing of two irrelevant motif. while other motifs can be well recognized. Thus the average level of accuracy of the information requested by the answer given by the system at $98 \%$ precisions. Kelok and Pucuak rabuang motif is not known because the motif has a rotation when the image is acquisitioned (Fig. 9)
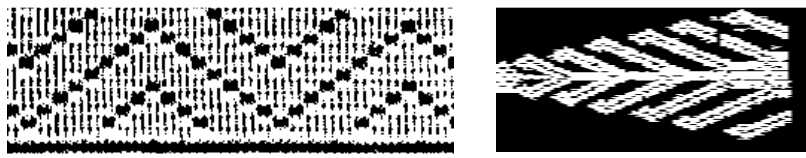

Fig. 9 Kelok and pucuak rabuang motifs

The graph of the results of the recall can be seen in Fig. 10.

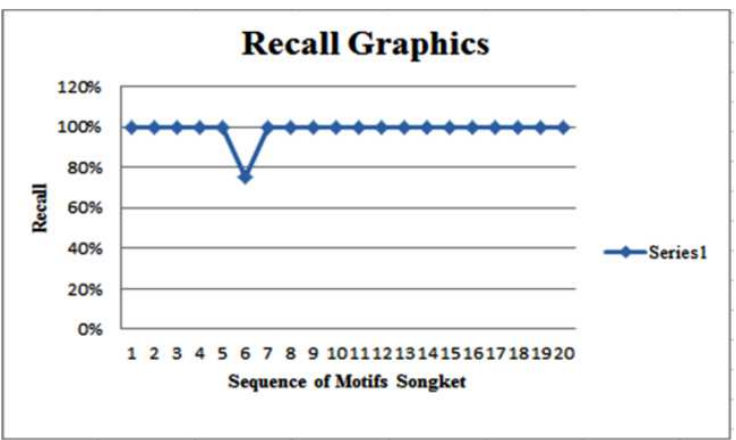

Fig. 10 Graph results precision whole motif songket

Fig. 10 shows that the motif of the $6^{\text {th }}$ (motif "kelok"), with 4 pieces motifs test values obtained recall value by $75 \%$, which is currently testing the relevant data is only three motif and one motif is irrelevant and unfounded, while 
other motifs can be recognized properly. Thus gained an average success rate in the system recognize which result of recall value of $99 \%$.

\section{CONCLUSIONS}

Extraction methods, the proposed classification, and BPNN can generate the database Chain-code features. Features probability as a texture pattern is independent of the size of the motif and is efficiently used for texture-based process of songket pattern recognition. Results of tests on 40 songket motifs show a good degree of accuracy where the precision value reached $98 \%$ and recall value reached $99 \%$. The failure caused by the introduction of more experienced motives rotation during image aquisis songket. This issue will be part of advanced research to pattern the resulting texture becomes independent of size and rotation.

\section{REFERENCES}

[1] Zhang, D, "Image Retrieval Based On Shape", Unpublished Dissertation, Monash University, 2002.

[2] VegadS. P. and ItaliyaP. K., "Image classification using neura network for efficient image retrieval", International Conference on Electrical, Electronics, Signals, Communication and Optimization (EESCO), pp. 1-6, 2015.

[3] Wang, Xiang-Yang, Zhang, Bei-Bei and Yang, Hong-Ying, "Content-based image retrieval by integrating color and texture features", Multimed Tools Appl, Vol. 68, No. 3, pp. 545-569, 2014
[4] Alhassan A. K. and. AlfakiA. A, "Color and texture fusion-based method for content-based Image Retrieval", International Conference on Communication, Control, Computing and Electronics Engineering (ICCCCEE), pp. 1-6,2017

[5] Madenda, S, Pengolahan Citra \& Video Digital, Penerbit Erlangga, Jakarta, 2015.

[6] Munir, A, Pengantar Pengolahan Citra, Penerbit Elek Media Computindo Kelompok Gramedia, Jakarta, 1992

[7] Na`am, Jufriadif, Harlan, Johan, Madenda, Sarifuddin and Wibowo, Eri Prasetio, " The Algorithm of Image Edge Detection on Panoramic Dental X-Ray Using Multiple Morphological Gradient (mMG) Method", International Journal on Advanced Science, Engineering and Information Technology, vol. 6, No. 6, pp. 1012-1018, 2016.

[8] Gonzales, R. C, \& Woods, R. E., Digital Image Processing : Third Edition. Pearson International Edition, 2002

[9] Prasetyo, E, Pengolahan Citra Digital dan Aplikasinya Menggunakan Matlab, Penerbit Andi Yogyakarta, 2011.

[10] Yuhandri, Madenda S., Wibowo E.P. dan Karmilasari ,"Object Feature Extraction of Songket Image Using Chain Code Algorithm", International Journal on Advanced Science, Engineering and Information Technology, Vol. 7, No. 1, hal. 235-241, 2017

[11] Kadir A. and Susanto A, Pengolahan Citra Teori dan Aplikasi, Andi, Yogyakarta, 2013

[12] Siang, Jong Jek, "Jaringan Syaraf Tiruan \& Pemrogramannya Menggunakan Matlab”, Andi, Yogyakarta, 2009.

[13] Nagathan A., Manimozhi dan Mungara J., "Content-Based Image Retrieval System using Feed-Forward Backpropagation Neural Network", International Journal of Computer Science and Network Security, Vol. 14, No. 6, pp. 70-77, 2014

[14] Gorunescu, F, "Data Mining Concepts, Models and Techniques", Verlag Berlin Heidelberg: Springer, 2011

[15] Lancaster F.W., "The Measurment and Evaluation of Library Service", Arlington: Information Resources Services, 1979 Pao M.L., "Concepts of Information retrieval", Colorado: Libraries Unlimited, 1989 